\title{
A Burocracia no Brasil: as bases da administração pública nacional em perspectiva histórica (1920-1945)
}

\author{
Carlos Henrique Assunção PAIVA
}

\begin{abstract}
Resumo: Este artigo se dedica à discussão, em perspectiva histórica, do desenvolvimento de modelos de administração pública clássicos e do fenômeno da burocratização no país. Em um primeiro momento, será apresentado o fenômeno burocrático em suas perspectiva mais global, relacionando-o a processos de mudanças sociais, em certo sentido globais e genéricos, como a industrialização e a urbanização. Em um segundo momento, será discutido o fenômeno da burocratização em uma perspectiva denominada micro, ao destacá-lo em sua dimensão políticoadministrativa. Procuraremos, então, investigar o processo de decisões e gerenciamento estatais que constituem a substância das reformas administrativas implementadas a partir dos anos 1930 até o final da gestão Vargas em 1945. Este período coincide com uma série de reformas político-administrativas que mudou, definitivamente, a relação entre estado/sociedade, bem como as relações sociais no âmbito da máquina pública no Brasil.
\end{abstract}

Palavras-chave: Burocracia; Administração pública; Governo Getúlio Vargas; Reforma administrativa.

\section{Introdução}

Este artigo se dedica à discussão, em perspectiva histórica, do desenvolvimento de modelos de administração pública

- Historiador, Mestre e Doutor em Saúde Coletiva (IMS/UERJ). Pesquisador do Observatório História e Saúde - OMS/OPAS COC/FIOCRUZ - 21040-361 - Rio de Janeiro - RJ - Brasil. E-mail: cpaiva@fiocruz.br 
clássicos e do fenômeno da burocratização no país. Importa identificar alguns sinais desse fenômeno social, político e econômico, cuja complexidade não pode com muita facilidade ser reduzida estritamente a nenhum aspecto da realidade humana ou mesmo social. Em virtude de suas diversas dimensões, até mesmo a psicológica, o fenômeno burocrático pode ser compreendido ao sabor de métodos e óticas variados. Assim, este texto não tem a pretensão de cobrir indiscriminadamente a literatura sobre o assunto, mas tão somente explorar certos argumentos com o fim de elaborar um quadro analítico bidimensional, apresentado a seguir.

Em um primeiro plano, será apresentado em perspectiva bastante ampla o fenômeno burocrático. Valendo-me da discussão levantada por autores como Fernando Uricoechea (1978), Mário Wagner Vieira da Cunha (1963), Juarez Brandão Lopes (1971), entre outros, se construirá a imagem do fenômeno burocrático em plano bastante global, relacionando-o a processos de mudanças sociais, em certo sentido globais e genéricos, como a industrialização e a urbanização.

Em um segundo momento, se procurará fechar o cerco, e abandonar noções quase abstratas - como modernização - para perceber o fenômeno da burocratização em uma perspectiva denominada micro, ao destacá-la em sua dimensão políticoadministrativa. Assim, quer-se dar particular atenção ao processo de decisões e gerenciamento estatais que constituem a substância das reformas administrativas implementadas pelos sucessivos governos, sobretudo a partir dos anos 1930. Aqui, serão de suma importância os trabalhos de Beatriz Warhlich (1983), de Lawrence Graham (1968) e de Edson Nunes (1997), além de dados produzidos a partir de fontes documentais, como o Diário de Getúlio Vargas e alguns periódicos.

Se no primeiro momento se ganha a compreensão de um fenômeno social amplo, com conexões importantes com outras arenas da vida social, bem como com o passado (a dimensão histórica da burocratização), no momento seguinte pode-se perceber mais precisamente seus conteúdos e formas, ao examinar de perto as reformas administrativas que 
A BUROCRACIA NO BRASIL: AS BASES DA ADMINISTRAÇÃO PÚBLICA...

implementaram maior grau de racionalização e burocratização na vida e na administração públicas do país.

É importante perceber que os dois enfoques não implicam contradição a respeito do conceito de burocracia e da administração pública, ao contrário, apontam noções eminentemente complementares.

\section{A Macroburocratização: o fenômeno em perspectiva ampla}

Fernando Uricoechea, em seu Minotauro Imperial (1978), observou a semente de uma rotina burocrática em tempos distantes. O fenômeno, segundo sua visão, confunde-se com a própria formação do estado nacional brasileiro, ainda nos tempos de Sua Majestade. O autor não identificou elementos objetivos que possam configurar ou desenhar certo grau de burocratização do Estado, ou mesmo da sociedade brasileira imperial. Assim, o fenômeno burocrático se confunde com uma centralização política, somado ao surgimento de uma organização administrativa que implementaria, pouco a pouco, o domínio do governo central nos assuntos locais. Uma organização, como se vê pelo título da obra de Uricoechea, hiperdimensionada, pois implica a imagem de algo grandioso e talvez incompatível com a época, pelo menos de acordo com a visão que se adota neste trabalho ${ }^{1}$.

Desse modo, na perspectiva de Uricoechea, o conflito entre o poder local - nas mãos de poderosos proprietários de terras - e o poder federal começa a ser favorável aos primeiros, não somente em razão das idas e vindas do processo de centralização política promovido pela União, mas também pelo caráter gradual do avanço na burocratização da administração do Estado. Isso porque, nesse ponto de vista, a substância da burocracia seria quase exclusivamente o jogo político que imprimiu uma movimentação de peças, de acordo com os interesses dos poderosos, sempre ávidos por mais poder. 
Não cremos que seja satisfatória essa percepção da burocracia como algo eminentemente colado à política. Deve-se estabelecer logo de início uma distinção entre os fenômenos da centralização e da burocratização brasileiras: embora em muitas ocasiões tenham relação estreita e por vezes direta, ambas possuem fontes de "legitimidade" distintas. Enquanto a centralização ou a descentralização dizem respeito à dimensão dos assuntos marcadamente políticos, ou seja, de como o governo (incluindo aí a burocracia pública) deverá atuar política, econômica e administrativamente, a burocracia possui dimensão mais ampla, e não se reduz exclusivamente à esfera das decisões políticas, como se verá mais adiante.

De qualquer maneira, na visão do autor, o estreito fosso entre burocracia e administração patrimonial começa a ser alargado ainda nos tempos do Imperador ${ }^{2}$. Segundo Fernando Uricoechea (1978, p.96), isso ocorre em primeiro lugar, em razão da atuação das próprias agências burocráticas centrais que pressionavam no sentido de progressiva racionalização na administração pública; em segundo lugar, pelo forte impacto racionalizador, na economia e na sociedade, produzido pela indústria do café; por último, em virtude da Guerra do Paraguai (1864-1870), que incitou a administração central a uma racionalização compulsória dos recursos e finanças nacionais, diante do conflito sem precedentes e de grandes proporções.

Apesar de todos os esforços rumo a uma concepção de administração pública mais técnica, racionalizada e burocrática ${ }^{3}$, em lugar da visão personalista, paternalista e patrimonialista da época, devemos localizar no período somente a gênese do processo de burocratização, pois este não se institui abruptamente. Não foi nesse contexto que as normas burocráticas procuraram indicar de maneira muito peculiar as "regras do jogo", mas sim, no correr dos anos 1920 e mais explicitamente após à Revolução de 1930, quando uma seqüência de reformas político-administrativas, dentro de um quadro geral de transformações sociais, conferiu nova organização ao aparelho do Estado. Desse modo, sustentar a existência de uma burocracia e de uma administração pública, 
A BUROCRACIA NO BRASIL: AS BASES DA ADMINISTRAÇÃO PÚBLICA...

aos moldes weberianos, durante o século XIX, seja talvez carregar nas cores uma realidade ainda bastante tímida e discreta.

Isso porque, no centro do processo de burocratização, encontra-se crescente transformação na sociedade: novos atores e novas classes sociais. Nesse ponto de vista, não há fartura de dados inteiramente confiáveis sobre o processo de burocratização e do desenvolvimento da administração pública no Brasil. Mário Wagner Vieira da Cunha (1963), Juarez Brandão Lopes (1971) e Edmundo Campos (1978) apresentam alguns dados esclarecedores nesse sentido. Segundo o último, em 1920, havia no país cerca de 37.644 indivíduos que ocupavam cargos e desempenhavam funções administrativas na indústria. Até 1950, ocorre formidável salto: há no país, nesse momento, cerca de 215 mil pessoas ligadas às atividades administrativas; $7,7 \%$ da população brasileira na ativa. Se se acrescentar a esses números as pessoas que ocupavam cargos burocráticos no Estado, se obteria um aumento importante. Basta observar os dados que o próprio autor traz. Em 1920, o funcionalismo federal era constituído por 65.533 indivíduos. Em 1965, temos 381.202 pessoas. Isso sem considerar as administrações estaduais e municipais e os militares.

\section{QUADRO 1}

ATIVIDADES ADMINISTRATIVAS/Nº FUNCIONÁRIOS/1000 HAB.

\begin{tabular}{|c|c|c|c|c|c|c|}
\hline $\begin{array}{l}\text { ANO } \\
\text { Local }\end{array}$ & 1920 & 1940 & 1950 & 1920 & 1940 & 1950 \\
\hline $\begin{array}{l}\text { Rio de } \\
\text { Janeiro }\end{array}$ & 59460 & 129152 & 160264 & 10 & 74 & 6 \\
\hline São Paulo & 25630 & 95311 & 92244 & 5 & 13 & 10 \\
\hline Brasil & 186075 & 482938 & 512644 & 6 & 12 & 10 \\
\hline
\end{tabular}

FONTE: tabela organizada a partir dos dados de Mário W. V. da Cunha, O Sistema Administrativo brasileiro. 
Juarez Brandão Lopes aborda o fenômeno da burocratização sob a ótica do que denomina a emergência de uma sociedade de massas no país. O autor coloca a burocracia dependente da industrialização e da urbanização, bem como da emergência de uma classe média urbana. Em razão disso, a modernização se localiza, em sua visão, quase inteiramente no centro-sul do país, acentuadamente no Rio de Janeiro e em São Paulo. Segundo o autor, "tudo está a indicar a alta concentração de estabelecimentos de elevado grau de racionalização (e burocratização) no centro-sul, abarcando parcela considerável do operariado da região e do valor da transformação industrial nela realizada" (1971, p. 99).

Para Lopes, o aumento nos níveis de burocratização tem a ver com a "extensão da organização onde rotinas racionais e impessoais, numa estrutura hierarquizada, prevalecem" (1971, p. 103). Não se trata de processo restrito ao mundo do business ou dos negócios privados. Nas palavras do autor, "pode-se mesmo falar na burocratização da sociedade" (idem). O fenômeno tem relação com o que Mário Vieira da Cunha interpretou como o fortalecimento do poder central, a influência crescente das massas urbanas no processo político e a permanência do coronelismo nas áreas mais remotas do país. Nesse quadro, tanto o sul como o norte do país viram crescer as nomeações em cargos públicos. Há, no entanto, segundo Lopes, diferenças de ordem quantitativa (ver também Cunha: 1963, p.112-114) e qualitativa na mudança: embora a região nordeste tenha vivido um processo de modernização mais discreto em números, se comparado ao centro-sul, lá o rumo ao moderno se deu também em consonância com a sobrevivência das elites oligárquicas; enquanto no sul, o mesmo processo respondeu à dinâmica de um fenômeno político diferenciado, como foi o populismo.

$\mathrm{Na}$ visão do autor, essa mudança social é gradativa, pois não se operou uma transformação abrupta e radical, de um modelo patrimonialista para um burocrático. Em suas palavras:

continuam, em boa medida, as práticas patrimonialistas (a de 'cuidar' de seus operários, a administração 'particularista' de 
A BUROCRACIA NO BRASIL: AS BASES DA ADMINISTRAÇÃO PÚBLICA...

pessoal etc), mas, misturadas, agora com tentativas de intensificação do ritmo de trabalho, preocupação esporádica de substituir por mão-de-obra mais barata (mulheres e menores) a mais cara (homens adultos), de aumentar aluguéis das casas da fábrica etc. Tais reações, por parte dos empregadores representam, todavia, quebra das relações tradicionais de trabalho e aumento de tensão entre operários e mestres. [...]. Os laços de obrigação e lealdade se quebraram. Um processo acumulativo e circular implanta-se e o comportamento e as relações afastam-se cada vez mais dos padrões patrimonialistas. O processo é irreversível e a sua resultante é a gradual desapropriação dos vínculos patrimonialistas" (Lopes,1971, p. 191-192).

Mário Vieira da Cunha chama a atenção para o fato de a administração pública não constituir jamais mera técnica apolítica, pois não possuía uma realidade com autonomia em relação às condições de organização do Estado, que vem a ser, na perspectiva do autor, o elemento ao qual o fenômeno da burocratização procurou fundamentalmente servir.

O autor considera que, durante o período imperial, não houve efetiva necessidade de atividades administrativas em bases burocráticas, em face do privatismo dominante nas relações entre as elites regionais. Em suas palavras, "durante o Império, a administração praticamente só alcançava reduzidos setores funcionais e áreas territoriais diminutas. O mais estava entregue ao poder dos clãs locais" (1963, p. 32).

Segundo o autor, a administração começou a se desenvolver ainda nos tempos imperiais, como forma de viabilizar os interesses das elites urbanas (burguesia mercantil), que não viam no antigo modelo das elites do hinterland a possibilidade de satisfazerem suas demandas políticas, econômicas e sociais. Nesse sentido, tal qual a concepção de Lopes, Cunha percebeu que o crescimento da administração pública brasileira se fez ao mesmo tempo que o crescimento das cidades e, portanto, tem a ver com o fenômeno da urbanização.

Vale salientar que esse modelo administrativo, extremamente vinculado à vida urbana, cresceu e se 
desenvolveu até a República Velha (1889-1930) eminentemente restrito às fronteiras estaduais. Apenas a partir dos anos de 1920, matérias relativas tanto à organização do trabalho como à educação e à saúde começam a deixar os fóruns de decisões dos estados para se tornarem questões de âmbito nacional. É nesse quadro que se deu a emergência de novos grupos econômicos e políticos, tais como o Partido Comunista (1922) e a Ação Integralista Brasileira (1932), responsáveis por forte aumento da pressão exercida sobre a administração. Curiosamente, as duas agremiações, apesar das profundas diferenças que as distinguiam, tinham por premissa básica um papel destacado do poder central na construção e organização da sociedade.

Assim, a partir dos anos 20, e muito claramente com Getúlio Vargas, o foco das disputas não mais se restringiu ao conflito por cargos menores na política clientelista de outros tempos. O que estava em jogo era a tomada de postos-chave para a definição das políticas econômicas e sociais do país. Nas palavras de Cunha:

Trata-se de pressão para que o Congresso se anule ou se renda às iniciativas legislativas tomadas pelo executivo, a portas fechadas, em gabinetes onde funcionam técnicos, que não são os técnicos encarregados das revisões jurídicas ou formais dos projetos, mas técnicos políticos, muitas vezes assessores ao mesmo tempo, e bem pagos, dos organismos de estudos das associações de classe (1963, p. 67-68).

Essa disputa pelo controle das decisões políticas, muitas vezes denominada centralização política, não passou despercebida pelos códigos e relações sociais, pois isso implicou a criação de nova maneira de perceber as relações dos indivíduos entre si e destes com as coisas, incluindo-se aí as relações de trabalho. De acordo com Robert Merton (1978), é na organização burocrática que o homem se dá conta de ser controlado pelas relações sociais e por sua relação com a máquina produtiva, o que os marxistas chamam de Modo de Produção. Assim, ficaria claro para o indivíduo que, para 
A BUROCRACIA NO BRASIL: AS BASES DA ADMINISTRAÇÃO PÚBLICA...

trabalhar, precisaria ser empregado. O sujeito não dispõe dos meios (equipamentos, máquinas) para executar seu serviço, o que, ao contrário, está sob a posse das burocracias tanto públicas como privadas.

Isso porque, em tese, o procedimento burocrático, em sua substância, tal qual defendido pelos tayloristas dos anos 20, rejeita na administração e em sua operação os desígnios da discussão política e ideológica. Aqui, os procedimentos seriam racionalizados, busca-se a precisão e a eficiência. $\mathrm{Na}$ ótica weberiana, o que ocorre é uma crescente divisão do trabalho; hierarquização de autoridade; normas extensivas e impessoais; separação entre administração e propriedade; seleção, salário e promoções baseados na competência técnica.

O importante nesse momento é se frisar a idéia de que a gradual passagem da dominação patrimonial à dominação burocrática do aparelho do Estado, a qual se manifesta pelo menos desde o século XIX, não merece ser confundida apenas com o surgimento de nova ordem administrativa, embora também o seja. Tem a ver, antes de tudo, com um paradigma moderno que, pela primeira vez, vincula o domínio público brasileiro a um conjunto de regras e normas diferentes daquelas que regem a esfera privada.

O surgimento da noção de que a sociedade deveria ser regida por um sistema objetivo de normas diferentes daquelas que orientam a vida dos indivíduos na esfera de suas vidas privadas provocou, quando de sua aplicação, importantes transformações na relação entre sujeitos sociais e o Estado. É nesse contexto, por exemplo, que surgem novos padrões de trabalho e ação administrativa mais especializados, tecnicamente racionalizados: a criação do concurso público para o ingresso no funcionalismo de carreira do Estado, em 1934; a fundação do Departamento Administrativo do Serviço Público (DASP), em 1938; a constituição de um estatuto para os funcionários públicos, em 1939, entre outras. De acordo com alguns autores (ver Uricoechea,1978, p. 281), ocorrem mudanças significativas nos padrões de solidariedade social e transformações mais em sintonia com a noção de Gesellschaft. 
Essas transformações, que fincam raízes no século XIX, têm também a ver com transformações em escala global. É durante a Primeira República que um acontecimento de impacto como a Primeira Guerra Mundial (1914-1918) provoca importantes mudanças na forma pela qual os atores sociais, políticos e intelectuais, apreenderam a realidade social de seu tempo. O conflito de escala mundial gerou na maioria dos países do globo profunda incerteza quanto à possibilidade de superação do atraso social via liberalismo, o que ficaria realmente óbvio a partir dos anos de 1930 (Ver Hobsbawn,1995, p. 29-219). Surge então a bandeira do Estado como uma espécie de entidade organizadora e preparada para intervir em uma realidade, no mínimo, potencialmente caótica.

Certamente um dos maiores impactos do período Vargas, o qual se estenderá pelo menos até o início do período militar na década de 1960, consiste na emergência daquilo que Eli Diniz (2000) chamou adequadamente de nova engenharia políticoinstitucional. No contexto dessa nova ordem, ocorreu uma mudança não só na estrutura do Estado, mas, sobretudo na relação que este mantinha com a sociedade. Houve, a um só tempo, um acréscimo do poder interventor do governo e uma abertura para a representação de grupos e segmentos sociais, antes alijados do jogo político. Tudo se tornava mais complexo.

Esse conjunto de fatos provocou certa decadência na influência das elites oligárquicas tradicionais, o que contribuiu para o fim do chamado estado oligárquico. A partir de 1930, sobretudo após a instauração do Estado Novo, em 1937, toda essa estrutura imposta "pelo alto" (Ver Castro Santos,1993), no correr dos tempos dos barões do café, sofreu uma crise em suas velhas formas de organização política e social. Daí em diante, as decisões relativas às políticas públicas passaram a depender, mais do que na década de 1920, de negociações com a burocracia central do governo. O que era gestado no microcosmo local, passava a ser objeto e resultado de uma conjunção muito mais complexa de fatores e atores sociais. É chegada a Era da Burocracia. 
A BUROCRACIA NO BRASIL: AS BASES DA ADMINISTRAÇÃO PÚBLICA...

\section{Getúlio Vargas e a bandeira da burocratização}

É difícil tratar todo o período em que Getúlio Vargas permaneceu no poder como simples seqüência de gestões. Foi mais, pois ao longo desses cerca de quinze anos ininterruptos no poder, o presidente teve que enfrentar diferentes desafios, que implicaram respostas distintas em forma e conteúdo: ora em sintonia, ora em conflito com a tradicional ordem social e política brasileira. Além disso, não é fácil tratá-lo como "mais um presidente", pois suas ações significaram, muitas vezes, nova rotina de funcionamento, tanto da política como da administração pública no país. Isso sem considerarmos as implicações sociais e econômicas dessas profundas mudanças operadas, sobretudo, nesses primeiros períodos (o Governo Provisório, 1930-1934; o Período Constitucional, 1934-1937, o Estado Novo, 1937-1945, fora o retorno democrático em 1951).

Sua ascensão ao poder decorreu de profundo e gradual desgaste das instituições políticas - e da própria Política - da Primeira República, as quais já não conseguiam responder com eficiência a um quadro social, em muitos sentidos, cada vez mais complexo na sociedade brasileira ${ }^{4}$.

De imediato ocorreu uma seqüência de importantes mudanças administrativas ${ }^{5}$. A começar pela nomeação dos interventores nos governos estaduais. Boa parte deles era oriunda do movimento tenentista, um dos ingredientes responsáveis pela crise da República oligárquica das primeiras décadas do século XX. Nomes hoje famosos como os de João Alberto, Juraci Magalhães, Juarez Távora, tomaram imediatamente conta das máquinas político-administrativas locais, com exceção do governador Olegário Maciel, primo de Gustavo Capanema, que permaneceu no poder em Minas Gerais, com o consentimento de Vargas. Nas palavras do presidente, sob o calor dos acontecimentos da revolução:

Começam as tentativas para a organização [pública]. Alguns nomes eu já trazia fixados, outros foram sendo sugeridos depois.

A mentalidade criada pela Revolução não admitia mais o 
emprego dos velhos processos, do critério puramente político (Diário de Getúlio Vargas, 01/11/1930, p.21, grifo meu)

Observa-se o contexto da dissolução dos legislativos federal, estaduais e municipais, a ocorrência de uma seqüência de importantes mudanças político-administrativas nos ministérios, bem como a criação de novas pastas. Todo esse turbilhão de mudanças conferiu nova feição ao executivo federal, com a implementação de uma renovada máquina administrativa nos governos, qualquer que fosse o nível de ação. Sobre a natureza e a eficiência ou não de todas essas mudanças operadas na estrutura do estado brasileiro, não parece ser suficiente encerrar todo o processo como um simples caminhar rumo à centralização política. Como se viu, toda a mudança era alimentada por transformações estruturais que se operavam na sociedade brasileira pelo menos desde o século XIX, alterações que iam do franco crescimento populacional até a lenta diversificação da economia do país nos anos de 1920, aliada ao surgimento de novos modos de vida.

Nesse sentido, não é possível reduzir o processo de mudança a um movimento de acontecimentos mais recentes, pois suas raízes situam-se em uma dinâmica de construção nacional que toma vulto, sobretudo, a partir da segunda metade do século XIX.

Pouco a pouco se atentava para o "problema da organização" no país. A chamada crise dos anos 20 marcou certa percepção, por parte de alguns segmentos intelectuais, de que o atraso brasileiro com relação às demais nações modernas e desenvolvidas poderia ser traduzido simplesmente pela ausência de uma estrutura político-administrativa com capacidade de afastar definitivamente o elemento contaminador dos atos políticos. A saída, como se começou a pregar na época, estava na Técnica, uma técnica cuja utopia e política residiam no fato de se pretender justamente apolítica ${ }^{6}$.

Assim, nas palavras de Luis Simões Lopes, o homem que, de 1938 até 1945, comandou boa parte das reformas administrativas do pós-1930, inicialmente à frente do Conselho 
A BUROCRACIA NO BRASIL: AS BASES DA ADMINISTRAÇÃO PÚBLICA...

Federal do Serviço Público, criado em 1936, e mais tarde à frente do DASP:

A situação da administração pública brasileira era então [até 1930] das mais lamentáveis, pois fora submetida, durante largos anos, a um regime eminentemente político, em que a escolha para os cargos públicos se fazia sob pressão dos políticos que apoiavam o governo (Depoimento de Luis Simões Lopes, 1986, p. 39-41)

É o início da construção de uma oposição ainda muito viva no imaginário atual, segundo a qual há uma benéfica neutralidade no campo da técnica e, de outro lado, uma espécie de desvirtuamento constante ou mesmo em potencial no campo da política. No final das contas, na esfera política não se poderia conceber eficiência, pois trata-se de um jogo em que a pauta dos interesses recai invariavelmente nas vontades particulares e privadas, em oposição aos interesses nacionais.

A partir desse contexto, por exemplo, Lawrence Graham (1968), em seu trabalho, parte de uma constatação de valor, ao considerar que, apesar de todo o investimento rumo a uma reforma institucional e administrativa, tomada de empréstimo, segundo ele, ao modelo norte-americano ${ }^{7}$, pouco impacto se estabeleceu em matéria de economia e eficiência nas rotinas das decisões governamentais no Brasil. Sua hipótese de trabalho é que houve importante discrepância entre as medidas estabelecidas no plano técnico-administrativo e as realidades existentes, constituídas a partir da movimentação dos atores sociais.

Entretanto, não parece oportuno considerarmos o sistema administrativo brasileiro como um modelo patológico, pois só o percebemos deformado quando o espreitamos a partir de uma escala de valores estranha à realidade local. Trata-se de valores que, como bem demonstrou Graham, não constituem expressão de algo universal, mas de uma realidade específica e alienígena ao contexto brasileiro. No final das contas, Graham pareceu contestar o estabelecimento de uma ética universalista, 
responsável, em última análise, pela reforma administrativa brasileira rumo a um quadro paradoxalmente estranho às suas necessidades (ver p.61). Dessa maneira, em suas palavras, "o sistema patrimonialista, como algo tradicional, entra no serviço público em contraste com a criação de um sistema de mérito, cuja seleção do mais competente constitui a base do sistema" (p.86). Assim, o autor concebe a burocratização não como um fenômeno puro ou acabado, mas sim essencialmente híbrido, de acordo com o sistema social observado.

Segundo os dados elaborados por Graham a partir das entrevistas que fez com funcionários públicos em meados do século passado, há alguns modelos de respostas bastante reveladores acerca do que os trabalhadores consideraram os maiores desafios rumo à burocratização do aparelho do estado, em uma perspectiva de economia e eficiência. Em primeiro lugar, chama-se a atenção para uma suposta inadequação das técnicas administrativas; em segundo lugar, para a dificuldade de organizar um programa de treinamento de pessoal; em terceiro, para a ausência de um plano de salários racional em um quadro de economia inflacionária; em seguida, comenta-se a inexistência de um plano de classificação das posições; e por último, chama-se a atenção para a lenta mobilidade dentro da estrutura funcional. Há ainda um entrevistado, com experiência na direção do departamento de um dos ministérios, que mencionou a existência de grandes dificuldades na coordenação da rotina entre as várias pastas do governo.

Suas entrevistas dizem muito a respeito das rotinas do pessoal de administração das repartições públicas, após e durante a gestão Vargas. Pode-se perceber que o já comentado significativo aumento no grau de complexidade, presente na criação de órgãos, cargos e funções, tornava mais complicada, em muitos sentidos, a execução das atividades administrativas diárias. Pois tal fato ironicamente colocava em risco a própria idéia de rotina, ao estabelecer importante instabilidade e rotatividade dentro do quadro de pessoal das instituições. Instabilidade não do ponto de vista de uma carreira, mas da ótica da formação de grupos de pessoas que se conheciam, do 
A BUROCRACIA NO BRASIL: AS BASES DA ADMINISTRAÇÃO PÚBLICA...

estabelecimento de laços primários que, em última análise, são responsáveis pela formação de grupos mais ou menos estáveis.

É nesse quadro que mais uma vez Luis Simões Lopes, visível entusiasta e executor privilegiado das reformas administrativas, não parecia compreender a resistência de setores e serviços públicos à gente enviada pelo departamento administrativo. De acordo com seu depoimento, em concurso para a Contadoria Geral da República:

os candidatos que foram aprovados nos primeiros lugares, nós destinamos à Contadoria Geral da República. Foram mal recebidos lá, chamavam eles de 'os sábios do DASP' etc. (Depoimento de Luis Simões Lopes, p.84)

Nesse sentido, é interessante reconhecer que Graham (1968) não só percebeu a burocracia e a administração pública como fenômenos estritamente técnicos, cilada em que muitos pensadores se viram presos, mas procurou desenhar paralelamente uma dimensão sociológica no processo. Além disso, tentou não operar um divórcio absoluto entre práticas patrimonialistas e burocráticas, ao perceber importante interação entre ambas. Contudo, foi Edson Nunes (1997) quem com mais detalhes e refinamento teórico-metodológico foi capaz de apontar as estreitas relações e tensões nas diferentes formas de convivência entre Estado e sociedade, assim como entre sociedade e indivíduo, nesse âmbito de discussão.

\section{Considerações Finais}

De início, tentou-se mostrar que o processo de burocratização, no âmbito da sociedade e do estado brasileiro, tem ao menos duas grandes dimensões. A primeira diz respeito a importantes transformações na estrutura e no ordenamento da sociedade. O velho padrão de vida rural, com sua visão de mundo patrimonialista, eminentemente calcado em valores aristocráticos, começou a se transformar, gradual e firmemente, 
a partir dos anos de 1920. Tudo, na visão de muitos contemporâneos, exigia novo ordenamento - que o período pós30 iria procurar garantir -, pois se tratava de mudanças jamais experimentadas no Brasil.

Nesse ordenamento, o papel da burocracia (a administração pública) era considerado importantíssimo, pois esta teria a capacidade de organizar e distribuir os objetivos, muitos dos quais diferentes entre si, sem, contudo, estabelecer compromisso mais significativo com um deles especificamente. Essas foram, por assim dizer, expectativas teóricas. Na prática, isso não ocorria, porque a burocracia revelou maior integração com aqueles setores da sociedade diretamente mais envolvidos com o crescimento econômico ${ }^{8}$.

A maneira pela qual as formas tradicionais de relacionamento social sobreviveram à burocracia, inspirada no modelo weberiano, sugere um conjunto de possibilidades explicativas. Em primeiro lugar, cabe perguntar até que ponto, no âmbito do estado brasileiro, a burocratização correspondeu à importação de idéias estrangeiras, como sugeriu Graham. Se se enxergar nisso tudo um movimento de clonagem ou cópia de projetos externos, sem sintonia com as mudanças que se operavam na sociedade brasileira, parece justo considerar que a reforma administrativa brasileira estava, desde o início, condenada à derrota. Algo que efetivamente não ocorreu, pelo menos integralmente.

Outra interpretação possível é considerar que o processo de burocratização não foi capaz de se opor às forças históricas de longa data na sociedade brasileira. Isto é, as forças de transformação não foram maiores ou mais intensas que as de conservação. Há aqui outro equívoco, que consiste em tratar a burocracia como algo inteiramente independente da sociedade brasileira, um fenômeno alienígena, algo efetivamente novo, o que não foi. $O$ intuito de levar a discussão em termos históricos foi, antes de tudo, tentar demonstrar que o movimento vinha também de tempo distante e, assim, não tinha surgido na sociedade como algo súbito ou como um processo importado. A 
A BUROCRACIA NO BRASIL: AS BASES DA ADMINISTRAÇÃO PÚBLICA...

burocracia estava, nesse sentido, muito mais próxima de uma reforma do que de uma revolução.

Por fim, tentou-se rejeitar a relação direta e causal que se tem estabelecido historicamente entre burocracia e centralização política. $O$ argumento é simples: a burocracia não pode ser reduzida com facilidade à dimensão dos assuntos políticos, embora, também pertença a essa arena de decisões. Procurou-se mostrar, nesse sentido, que a burocracia é um fenômeno bastante difuso, que encontrou manifestação em diversas áreas da vida social. Por isso, a forma pela qual vai se expressar, seja política, econômica ou sociologicamente, é relativamente distinta, de arena para arena.

No âmbito político, a burocracia certamente tinha muito a ver com um ímpeto, mais ou menos gradual, de centralização política, que tomou vulto justamente a partir dos anos de 1920. Centralização, como se viu, forjada no campo das idéias e propostas vigentes no correr dos anos 20, quando se acreditava, por exemplo, que a saída para os problemas da administração dos recursos da saúde residia na criação de um aparato administrativo centralizado. É certo que isso tem relação com a discussão econômica, pois muitos acreditavam que o Estado deveria ser o grande gestor dos acontecimentos econômicos, um centralizador contra o caos, à feição do que havia ocorrido em outras experiências históricas, como a Restauração Meiji, a Prússia do século XVIII, a Alemanha e a Itália do século XIX.

$\mathrm{Na}$ esfera sociológica, tudo se passou de maneira mais complicada, pois aqui se tratou de um processo de mudança social que se desenrolou não exclusivamente em estruturas econômicas ou políticas, pois constituiu, em última análise, um processo mental e cultural. Trata-se de reformas administrativas que pressupunham mudança significativa nos padrões de comportamento dos atores sociais, o que de fato não ocorreu; tais reformas acabaram por gerar uma espécie de descompasso entre as diferentes esferas da vida social: o desconforto de uma época.

O centro do conflito, se assim se pode considerar, localizou-se mais decisivamente na estrutura administrativa que HISTÓRIA, São Paulo, 28 (2): 2009 
geria a máquina publica do Estado. Tentou-se mostrar como a instituição do sistema de mérito, em alguma medida, representava um desafio à velha ordem das coisas, pois se desligava do velho patrimonialismo em suas várias dimensões sociais e políticas, desde um "inocente" acordo entre pares, até manobras mais articuladas dos partidos políticos, que tinham por costume premiar serviços prestados com cargos públicos.

Apesar do desarranjo provocado pelos concursos públicos nos primeiros tempos, mais potencial que efetivo, está suficientemente claro que houve significativa diversificação de atores sociais na gerência da máquina pública brasileira, a partir dos anos de 1930. Diversificação que vinha a ser o eco de transformações sociais fundamentais na sociedade. Com a burocratização do Estado e a criação de novos cargos, funções e órgãos administrativos, a máquina pública se transformou muito rapidamente em um organismo altamente complexo. Em tese, o que se ganhou em eficiência administrativa, se perdeu em eficácia política ${ }^{9}$, sobretudo com a tendência ao insulamento burocrático em alguns setores de decisão.

\section{Referências Bibliográficas}

\section{Livros e Artigos}

CARVALHO, José Murilo de. A construção da Ordem: a elite política imperial. Brasília: Ed. Da UnB, 1980. 202 p.

CAMPOS, Edmundo. "Introdução". Sociologia da Burocracia. Rio de Janeiro: Zahar Editores, 1978. 153 p.

CASTRO-SANTOS, Luiz Antônio de. "A reforma sanitária Pelo Alto: o pioneirismo paulista no início do século XX". Dados. Vol. 36. N 3, 1993. CUNHA, Mário Wagner Vieira da. O sistema administrativo brasileiro (1930-1950). (Série VI, Sociedade e Educação. Coleção O Brasil Urbano). Rio de Janeiro: Instituto acional de Estudos Pedagógicos, 1963. 179 p. DINIZ, Eli. "Engenharia institucional e políticas públicas: dos conselhos técnicos às câmaras setorias". In: Dulce Pandolfi (org.) Repensando o Estado Novo. Rio de Janeiro: FGV,1999. 345 p. 
A BUROCRACIA NO BRASIL: AS BASES DA ADMINISTRAÇÃO PÚBLICA...

GRAHAM, Lawrence S. Civil service reform in Brazil: principles versus practice.Texas: University of Texas Press, 1968. $233 \mathrm{p}$.

HOBSBAWN, Eric. Era dos extremos. O breve século XX (1914-1991). Tradução de Marcos Santarrita. São Paulo: Companhia das Letras, 1995. $598 \mathrm{p}$.

IANNI, Octávio. Formação do Estado populista na América Latina. [2 ed.] São Paulo: Ática, 1989. P. 40-59.

LOPES, Juarez Rubens Brandão. Desenvolvimento e mudança social: formação da sociedade urbano-industrial no Brasil. [2 ${ }^{\circ}$ ed.] São Paulo: Ed. Nacional, 1971. 215 p.

MERTON, Robert. "Estrutura burocrática e personalidade". CAMPOS, E. (org.) Sociologia da Burocracia. Rio de Janeiro: Zahar Editores, 1978. $153 \mathrm{p}$

NUNES, Edson. A gramática política do Brasil. Clientelismo e insulamento burocrático. Rio de Janeiro: Jorge Zahar Editor; Brasília: Escola Nacional de Administração Pública, 1997. 146 p.

REIS, Elisa. "Poder privado e construção de estado sob a Primeira República". In: Renato R. Boshi (org.) Corporativismo e desigualdade: a construção do espaço público no Brasil. Rio de Janeiro: Ed. IUPERJ, 1991. pp. 43-68.

RIGGS, Fred W. "Los burocratas y el desarollo político: una concepcion paradojica". J. Lapalombara (org.) Burocracia y desarollo político. Buenos Aires: Editorial Aidos, 1963. pp. 113-156.

WAHRLICH, Beatriz de Souza. Reforma administrativa na era Vargas. Rio de Janeiro: Ed. Fundação Getúlio Vargas, 1983. 908 p.

URICOECHEA, Fernando. O minotauro imperial: a burocratização do estado patrimonial brasileiro no século XIX. (Coleção Corpo e Alma do Brasil, direção de Fernando Henrique Cardoso). Rio de Janeiro/São Paulo: DIFEL, 1978. 332 p.

\section{Documentos}

Getúlio Vargas: diário. (Vol.1, 1930-1936; Vol.2, 1937-1942) São Paulo: Siciliano/Rio de Janeiro:Fundação Getúlio Vargas, 1995.

CPDOC/FGV. Arquivo Gustavo Capanema. Rio de Janeiro, Centro de Pesquisa e Documentação, Fundação Getúlio Vargas. Assuntos administrativos. 
PAIVA, Carlos Henrique Assunção. The Bureaucracy in Brazil: the foundations of the national administration in historical perspective (1920-1945). História, v.28, n.2, p.775-796, 2009.

\begin{abstract}
This article discuss, in prospect historic, the public administration classics models and the burocratic phenomenon in Brazil. On the one hand, it shall presented the bureaucratic phenomenon into a wide perspective, linking it to a social changes processus, like the industrialization and the urbanization. On the other hand, it shall discussing the bureaucratization phenomenon into a perspective denominated micro, to detachable it into a administrative politic dimension. The focus is the decision process and state management that are the substance of the administrative reforms made from the 1930' until the Vargas management in 1945. This period coincides with a series of political administrative reforms than it shifted, definitely, the relationship between state and society, as well as the acquaintanceship into the Brazilian state.
\end{abstract}

Keywords: Bureaucracy; Civil service; Getúlio Vargas` government; Administrative Reform.

\title{
NOTAS
}

1 Segundo Elisa Reis, "via de regra, a discussão do processo de construção do estado nacional no Brasil concentra-se no período imperial" (1991:p. 44), exatamente com trabalhos como o de Fernando Uricoechea, além de José Murilo de Carvalho, com A construção da Ordem: a elite política imperial. Brasília: Ed. Da UnB, 1980. De lá pra cá, a Primeira República tem sido menos tratada como um eclipse nesse processo, e a construção do Estado tem sido vista como um processo amplo e relativamente contínuo, isto é, não mais como um evento abrupto, ocorrido na época imperial.

2 Lawrence Graham (1968) observa, como ponto de partida da construção de uma rotina e de instituições burocráticas no Brasil, a transferência da Corte portuguesa em 1808, quando a então colônia passa à categoria de Império Unido, e torna-se assim locus preferencial dos administradores lusos. 
A BUROCRACIA NO BRASIL: AS BASES DA ADMINISTRAÇÃO PÚBLICA...

${ }^{3}$ Uricoechea lembra que ocorrem na época mudanças importantes na imagem do Imperador e do governo. O símbolo do monarca, por exemplo, começa a desaparecer gradualmente dos documentos oficiais, para ser substituído por noções impessoais como "este governo", "o país" ou simplesmente "Brasil" (1978, p.97)

${ }^{4}$ Sobre a decadência do chamado estado oligárquico não só no Brasil, mas também como fenômeno mais ou menos uniforme em toda a América Latina, consulta-se o trabalho de Octávio Ianni, $A$ formação do Estado populista na América Latina (Série Fundamentos, $n^{\circ} 37$ ). São Paulo: Ática, 1989.

${ }^{5}$ Mario Wagner Vieira da Cunha (1963, p. 46-50), por sua vez, acredita que os primeiros tempos do governo Vargas, sobretudo durante o governo provisório, representaram um período em que, por conta das grandes dificuldades orçamentárias, nada foi feito para se alterar a estrutura administrativa do Estado. Tenta-se mostrar que via manobras, em boa parte "sem aumento de despesas", Vargas de imediato promoveu um salto na burocratização do aparelho da máquina pública estatal.

${ }^{6}$ Como sugere Lawrence Graham (1968), em um primeiro momento, a teorização norte-americana sobre administração pública foi caracterizada pelo "machine model", ao excluir o comportamento humano como variável na dinâmica administrativa. Desse modo, percebiam-se os sujeitos não como sujeitos, mas como criaturas eminentemente passivas nas relações de trabalho. (Ver principalmente capítulo 3, "The theoretical foundations of the reform movement").

7 Encontra-se no Arquivo Capanema, no CPDOC/FGV, variada documentação a respeito da influência de alguns modelos administrativos estrangeiros. Há, por exemplo, documentação a respeito dos serviços do Ministério da Instrução Pública da Grécia (em francês), documentação do Conselho Superior de Administração Pública da Itália, original de 1928, além de amplo quadro de toda a estrutura político-administrativa alemã (em português e alemão). No entanto, a influência majoritária norte-americana, nesse campo, é amplamente demonstrada pela literatura, o que condiz com os seguintes depoimentos: "À noite recebi visita de Luis Simões Lopes [presidente do DASP], que foi com o Oswaldo [Aranha] aos Estados Unidos e esteve dando suas impressões do que observou quanto à organização administrativa." (Diário de Vargas, 26/03/1939). Já Simões Lopes, quando indagado a respeito da influência francesa na reforma 
administrativa em curso, respondeu: "Não, a França, nesse tempo, era muito, digamos assim, retrógrada, em relação a esses processos modernos de administração" (Depoimento de Simões Lopes, FGV, p.68).

8 O fundamental é que "ela", a burocracia, não foi e não é uma categoria uniforme. Em última análise, ela não fez isso ou aquilo, como primeira pessoa, mas foi um processo que, ao representar uma estruturação importante para as relações sociais, tanto no âmbito da sociedade como no do Estado, imprimiu novo código de condutas e padrões de comportamento sociais.

${ }^{9}$ Por isso, Fred W. Riggs considerou que "um funcionário estranho ao lugar, com maior experiência e capacitação formal, talvez estimule o desenvolvimento econômico com maior rapidez, mas não o desenvolvimento político" (1963, p. 129; tradução minha).

Artigo recebido em 08/2009. Aprovado em 11/2009. 